\title{
INTERACTION OF A HUMAN PLASMA LIPID TRANSFER PROTEIN COMPLEX WITH LIPID MONOLAYERS
}

\author{
JUDITH A.K. HARMONY ${ }^{a}$, RICHARD L. JACKSON ${ }^{b}$, JAHEI IHM ${ }^{a}$, JEFF L. ELLSWORTH ${ }^{b}$ and RUDY A. DEMEL $^{c}$ \\ ${ }^{a, b}$ Division of Lipoprotein Research, ${ }^{a}$ Department of Biological Chemistry and ${ }^{b}$ Department of Pharmacology and Cell Biophysics, \\ University of Cincinnati College of Medicine, Cincinnati, $\mathrm{OH} 45267$ (U.S.A.) and ${ }^{c}$ Biochemical Laboratory, State University of Utrecht, \\ Padualaan 8, Utrecht (The Netherlands)
}

(Received December 22nd, 1981)

Key words: Lipoprotein metabolism; Lipid-protein interaction; Lipid transfer complex; Lipid monolayer

The interaction of a purified human plasma lipid transfer complex with cholesteryl ester, triacylglycerol and phosphatidylcholine in binary and ternary lipid monolayers was investigated. The lipid transfer complex, designated LTC, catalyzes the removal of cholesteryl oleate and triacylglycerol from phosphatidylcholine monolayers. Preincubation of LTC with p-chloromercuriphenyl sulfonate inhibits LTC-catalyzed removal of triacylglycerol; cholesteryl ester removal is not affected. The rate of LTC-facilitated removal of cholesteryl oleate from a phosphatidylcholine monolayer depends on the amount of LTC added to the subphase up to 100 $\mu \mathrm{g}$ protein. In addition, the rate of the LTC-catalyzed transfer of cholesteryl oleate to the subphase increases linearly as the amount of cholesteryl oleate in the monolayer increases to $6 \mathrm{~mol} \%$. LTC also removes cholesterol from phosphatidylcholine-cholesterol monolayers, albeit at a rate which is $15 \%$ of that for removal of cholesteryl oleate. The ability of LTC to facilitate triacylglycerol and cholesteryl ester removal depends on the composition of the monolayer. Phosphatidylcholine supports cholesteryl ester transfer whereas sphingomyelin-cholesteryl ester monolayers are almost refractory to LTC. In contrast, LTC removes triacylglycerol from either a phosphatidylcholine or a sphingomyelin monolayer. The results suggest the existence of at least two lipid transfer proteins, one of which catalyzes the removal of cholesteryl ester and the other triacylglycerol. The role of these proteins as they relate to lipoprotein metabolism is discussed.

\section{Introduction}

Plasma lipoproteins are the major carriers of triacylglycerols and cholesteryl esters in the circulation. Chylomicrons and very low density lipoproteins (VLDL) transport triacylglycerols of ex-

\footnotetext{
Abbreviations used: $\mathrm{LDL}$, low density lipoproteins $(d$ l.02-1.05 $\mathrm{g} / \mathrm{ml})$; VLDL, very low density lipoproteins $(d<1.006 \mathrm{~g} / \mathrm{ml})$; $\mathrm{HDL}$, high density lipoproteins $(d 1.063-1.21 \mathrm{~g} / \mathrm{ml})$ subfractionated into $\mathrm{HDL}_{2}(d 1.063-1.12 \mathrm{~g} / \mathrm{ml})$ and $\mathrm{HDL}_{3}(d 1.12-$ $1.21 \mathrm{~g} / \mathrm{ml}$ ); LTC, lipid transfer complex; DOPC, 1,2-dioleoylphosphatidylcholine; DPPC, 1,2-dipalmitoylphosphatidylcholine; PCMPS, p-chloromercuriphenyl sulfonate.
}

ogenous and endogenous origin, respectively, whereas cholesteryl esters are transported by low density (LDL) and high density (HDL) lipoproteins. The plasma lipoproteins are pseudomicellar structures with the neutral lipids contained within a central core surrounded by an outer monolayer of phospholipid, unesterified cholesterol and protein (for review, see Refs. 1-5). Of the phospholipid constituents, approx. $75 \%$ is phosphatidylcholine and $20 \%$ sphingomyelin [1] with the balance phosphatidylethanolamine, phosphatidylserine, and phosphatidylinositol.

Although it has not been measured directly, it is assumed that the lipoprotein surface monolaye 
contains small amounts of neutral lipid. The assumption that neutral lipids are miscible with phospholipids is consistent with the fact that cholesteryl esters can be dispersed in either monolayer [6-9] or bulk phospholipid systems [10-13]. Smaby et al. [7] demonstrated that cholesteryl oleate and dioleoylphosphatidylcholine form stable monolayers with a solubility limit of $43 \mathrm{~mol} \%$ for the cholesteryl ester. According to Janiak et al. [11], a bulk lipid system of hydrated dimyristoylphosphatidylcholine accommodates less cholesteryl ester; the ternary system was completely miscible to approx. $5 \mathrm{~mol} \%$ of cholesteryl myristate. Further evidence for a surface location of neutral lipids within the outer monolayer of the lipoprotein particle is provided by the fact that cholesteryl esters and triacylglycerols transfer between lipoprotein particles. It is known that the rate of transfer of neutral lipids is enhanced by specific plasma lipid exchange proteins [14-19] which can be isolated from lipoprotein-free plasma. Detailed information as to the physical-chemical properties of these transfer proteins is, however, limited. Furthermore, nothing is known about the molecular mechanism by which lipids are transferred. The purpose of the present study was to assess the interaction of a purified lipid transfer protein complex (LTC) with monolayer lipids. In this study, monolayers of phospholipid containing triacylglycerol or cholesteryl ester were prepared and LTC was injected under the monolayer so as to determine the rate of lipid removal from the interface and the specificity of the reaction. The results of this study show that LTC removes both cholesteryl oleate and triacylglycerol from phospholipid monolayers.

\section{Materials and Methods}

Lipids. 1,2-Dioleoylphosphatidylcholine (DOPC) was synthesized as described previously [20]; 1-stearoyl-2-oleoylphosphatidyl[ $N$-methyl${ }^{14} \mathrm{C}$ choline (specific activity, $50 \mathrm{mCi} \cdot \mathrm{mmol}^{-1}$ ) was synthesized using $\left[{ }^{14} \mathrm{C}\right]$ methyl iodide [21]. [26${ }^{14} \mathrm{C}$ Cholesterol (Amersham, Inc., $58 \mathrm{mCi}$. $\mathrm{mmol}^{-1}$ ) and unlabeled cholesterol (Sigma Chemical Co.) were purified by thin-layer chromatography. $\left[1-{ }^{14} \mathrm{C}\right]$ Cholesteryl oleate (New England Nuclear, $55 \mathrm{mCi} \cdot \mathrm{mmol}^{-1}$ ), greater than $99 \%$ pure as determined by thin-layer chromatography and scintillation scanning, was used without further purification. Tri $\left[1-{ }^{14} \mathrm{C}\right]$ oleoylglycerol $(95 \mathrm{mCi}$. $\mathrm{mmol}^{-1}$ ) was purchased from New England Nuclear and was repurified by thin-layer chromatography. Tri $\left[9,10(n)-{ }^{3} \mathrm{H}\right]$ oleoylglycerol $(121 \mathrm{Ci}$ - $\mathrm{mmol}^{-1}$, New England Nuclear) was used without further purification. Bovine brain $[N$ methyl- $\left.{ }^{14} \mathrm{C}\right]$ sphingomyelin $\left(60 \mathrm{mCi} \cdot \mathrm{mmol}^{-1}\right)$ was purchased from Amersham. Bovine brain sphingomyelin and cholesteryl oleate were purchased from Applied Science. Phosphatidyl$\left[{ }^{14} \mathrm{C}\right]$ inositol $\left(1 \mathrm{mCi} \cdot \mathrm{mmol}^{-1}\right)$ was prepared as described previously [22]. The purity of each lipid was checked by thin-layer chromatography in two solvent systems: hexane/ethanol/acetic acid (90: 10:1, v/v) and chloroform/methanol/acetic acid/water $(90: 30: 8: 2.8, \mathrm{v} / \mathrm{v})$. All stock lipid solutions were stored under $\mathrm{N}_{2}$ at $4^{\circ} \mathrm{C}$ and were used within two days. Fatty acid-free bovine serum albumin (fraction V), fatty acid-poor human serum albumin and $p$-chloromercuriphenyl sulfonate were obtained from Sigma Chemical Co.

Isolation of lipoproteins and apoproteins. VLDL $(d<1.006 \mathrm{~g} / \mathrm{ml})$, LDL $(d 1.02-1.05 \mathrm{~g} / \mathrm{ml})$ and $\mathrm{HDL}_{3}(d 1.12-1.21 \mathrm{~g} / \mathrm{ml})$ were isolated from the plasma of fasted normolipemic subjects by sequential ultracentrifugal flotation in solutions of $\mathrm{KBr}$; a Beckman Ti 50.2 rotor operated at $48000 \mathrm{rev}$. $\min ^{-1}$ for $20 \mathrm{~h}$ and $8^{\circ} \mathrm{C}$ was used for all separations. Each lipoprotein class was refloated at its respective density and stored at $4^{\circ} \mathrm{C}$ under $\mathrm{N}_{2}$ in $\mathrm{KBr}$. Lipoproteins were dialyzed against a standard buffer of $10 \mathrm{mM}$ Tris- $\mathrm{HCl}, \mathrm{pH} 7.4$, containing $0.9 \% \mathrm{NaCl}, 1 \mathrm{mM}$ EDTA and $0.01 \%$ sodium azide.

Apolipoprotein $\mathrm{C}-\mathrm{I}$ and apolipoprotein $\mathrm{C}-\mathrm{III}_{2}$ (containing $2 \mathrm{~mol}$ sialic acid per mol protein) were isolated from VLDL by gel filtration of apoVLDL on Sephadex G-75 followed by ion-exchange chromatography on DEAE-Sephacel at $4^{\circ} \mathrm{C}$ in $6 \mathrm{M}$ urea as described previously [23]. Each apolipoprotein was homogeneous as determined by isoelectric focusing [24] and by amino acid analysis. Apolipoprotein A-I was isolated from HDL [25]. Apolipoprotein $\mathrm{E}$ was isolated from human VLDL by chromatography on heparin-Sepharose [26]. Apolipoprotein A-I and apolipoprotein E were homogeneous as determined by polyacrylamide gel 
electrophorsis in sodium dodecyl sulfate [27] and by amino acid analysis. Apolipoproteins were dissolved to $1 \mathrm{mg} / \mathrm{ml}$ protein in $0.01 \mathrm{M}$ Tris- $\mathrm{HCl}, \mathrm{pH}$ 7.4 , containing ultrapure $6 \mathrm{M}$ guanidine- $\mathrm{HCl}$ (Pierce Chemical Co.), and were incubated at $22^{\circ} \mathrm{C}$ for $2 \mathrm{~h}$ prior to dialysis against $0.01 \mathrm{M}$ Tris- $\mathrm{HCl}$, $\mathrm{pH} \mathrm{7.4,} \mathrm{and} \mathrm{injection} \mathrm{underneath} \mathrm{the} \mathrm{lipid} \mathrm{mono-}$ layer. Sphingomyelin-apolipoprotein A-I and sphingomeylin-apolipoprotein $\mathrm{E}$ complexes were prepared by incubating sphingomyelin $(3 \mathrm{mg})$ and apolipoprotein A-I or apolipoprotein E (3 mg) for $12 \mathrm{~h}$ at $37^{\circ} \mathrm{C}$ in a total volume of $1.0 \mathrm{ml}$ of $0.01 \mathrm{M}$ Tris- $\mathrm{HCl}, \mathrm{pH} \mathrm{7.4/0.9 \%} \mathrm{NaCl}$.

Isolation of the lipid transfer complex.The lipid transfer complex was isolated from the $d<1.21$ $\mathrm{g} / \mathrm{ml}$ infranatant fraction of human plasma as described previously [19]. The purification procedure involves chromatogaphy of the $d<1.21 \mathrm{~g} / \mathrm{ml}$ infranatant fraction on phenyl-Sepharose followed by sequential elution of the active fraction from CM-cellulose and concanavalin A-Sepharose. The active preparation transferred lipoprotein triacylglycerol, cholesteryl ester and phospholipid and contained three proteins of apparent molecular weights 80000,61000 and 33000 as determined by polyacrylamide gel electrophoresis in SDS-urea [27]. The cholesteryl ester and phosphatidylcholine transfer activity of the complex was determined using double-labeled HDL containing $\operatorname{di}\left[{ }^{14} \mathrm{C}\right]$ palmitoylphosphatidylcholine $\left.\left({ }^{14} \mathrm{C}\right] \mathrm{DPPC}\right)$ and $\left[{ }^{3} \mathrm{H}\right]$ cholesteryl ester $\left(\left[{ }^{3} \mathrm{H}\right] \mathrm{CE}\right)[19]$. The assay mixtures contained $\left[{ }^{3} \mathrm{H}\right] \mathrm{CE}-\left[{ }^{14} \mathrm{C}\right] \mathrm{DPPC}$-labeled HDL (57 $\mu \mathrm{g}$ protein, $24.5 \mathrm{nmol}$ cholesteryl ester (3571 $\mathrm{dpm} / \mathrm{nmol}$ ), $46.5 \mathrm{nmol}$ DPPC [69.6 dpm/nmol]) and unlabeled LDL (345 $\mu \mathrm{g}$ protein, $960 \mathrm{nmol}$ cholesteryl ester, $350 \mathrm{nmol}$ DPPC) and LTC (10$100 \mu \mathrm{g}$ protein). With these assay conditions the LTC transferred $45.2 \mathrm{nmol}$ phosphatidylcholine and $53.6 \mathrm{nmol}$ cholesteryl ester per $\mathrm{h}$ per $\mathrm{mg}$ protein. The protein-facilitated exchange of triacylglycerol was determined by measuring the transfer of tri[ $\left[{ }^{3} \mathrm{H}\right]$ oleoylglycerol from LDL to $\mathrm{HDL}$. Tri $\left[{ }^{3} \mathrm{H}\right.$ [oleoylglycerol was incorporated into LDL by injection of $500 \mu \mathrm{Ci}$ tri[9,10(n)${ }^{3} \mathrm{H}$ ]oleoylglycerol dissolved in $0.25 \mathrm{ml}$ ethanol into $60 \mathrm{ml}$ of freshly-collected human plasma. The plasma was incubated for $12 \mathrm{~h}$ at $37^{\circ} \mathrm{C}$ and the radiolabeled lipoproteins were isolated within the density limits described above. The incubation mixture contained LDL ( $5 \mathrm{nmol}$ triacylglycerol $(12220 \mathrm{dpm} / \mathrm{nmol}))$, HDL (12 nmol triacylglycerol), and lipid exchange complex (10-100 $\mu \mathrm{g}$ protein). The LTC-factilitated rate of triacylglycerol exchange was $6.25 \mathrm{nmol}$ per $\mathrm{h}$ per $\mathrm{mg}$ protein. In all assays, the lipoprotein classes were reisolated by ultracentrifugation at density 1.063 $\mathrm{g} / \mathrm{ml}$ in $\mathrm{KBr}$. At the final stage of purification, the LTC preparation was devoid of lecithin: cholesterol acyltransferase (LCAT) activity [28].

Interfacial measurements. Monolayer studies were performed in a $15 \mathrm{ml}$ Teflon trough $(5.4 \times$ $5.9 \times 0.5 \mathrm{~cm})$. The subphase was stirred with a magnetic bar. The trough was filled with $0.01 \mathrm{M}$ Tris- $\mathrm{HCl}, \mathrm{pH} \mathrm{7.4,} \mathrm{containing} 0.9 \% \mathrm{NaCl}$. The surface pressure was determined with a recording Beckman LM 500 electrobalance equipped with a platinum plate $1.96 \mathrm{~cm}$ wide. The surface radioactivity was measured with a gas flow detector (Nuclear Chicago 8731) situated $0.3 \mathrm{~cm}$ above the interface. The gas used was helium $/ 1.3 \%$ butane. Lipid films were spread from a chloroform/ methanol $(90: 10, \mathrm{v} / \mathrm{v})$ solution until the desired interfacial pressure was reached. All measurements were performed in a thermostatically controlled box filled with nitrogen [22]. Surface pressure-area determinations were determined using a Teflon trough $32.2 \mathrm{~cm}$ long $\times 17.2 \mathrm{~cm}$ wide. The compression rate was $25 \AA^{2} /$ min per molecule.

To study the interaction of the LTC with lipids, lipids were spread to give an initial surface pressure of $20 \mathrm{mN} / \mathrm{m}$. After the surface pressure and radioactivity had stabilized (usually $15 \mathrm{~min}$ ), the LTC and various other proteins were injected under the monolayer through a hole of $0.8 \mathrm{~cm}$ at an extended corner of the Teflon trough.

Analytical methods. Protein concentrations were determined by the method of Lowry et al. [29], using $1 \%$ sodium dodecyl sulfate to clarify the samples; bovine serum albumin (Sigma Fraction V, fatty acid-free) was the standard. Phospholipid phosphorus was determined by the method of Bartlett [30]. Total acylglycerol was determined enzymatically using the Triglyceride Test Combination Kit (Boehringer Mannheim). Cholesterol and cholesteryl esters were determined by the method of Roeschlau et al. [31] using the Cholesterol Test Combination Kit (Boehringer Mannheim). 


\section{Results}

\section{LTC-facilitated removal of lipid from monolayers}

The lipid transfer complex isolated from human plasma catalyzes the transfer of cholesteryl esters, triacylglycerols and phospholipids between lipo-

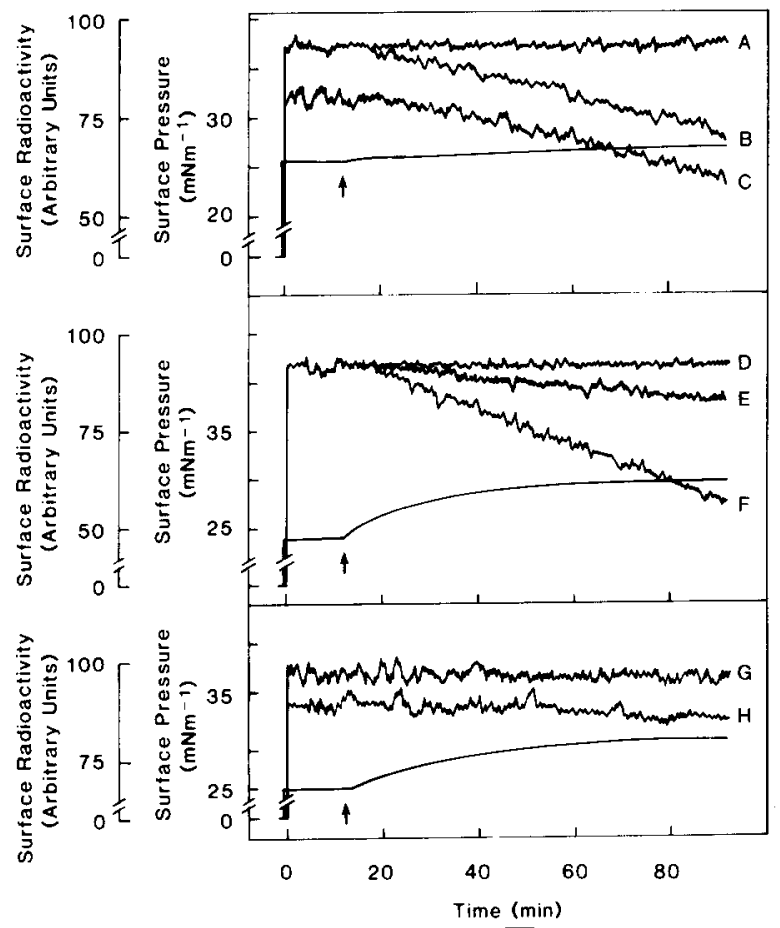

Fig. 1. Effect of lipid transfer complex (L $\overline{\mathrm{TC}}$ ) on the removal of monolayer lipids. Top panel. The monolayer consisted of $8 \mathrm{nmol}$ dioleoylphosphatidylcholine (DOPC) containing $5 \mathrm{~mol} \%$ $\left[{ }^{14} \mathrm{C}\right]$ cholesteryl oleate at an initial surface pressure of 20 $\mathrm{mN} / \mathrm{m}$. Curve A represents surface radioactivity in the absence of LTC. As is indicated by the arrow, LTC $(50 \mu \mathrm{g})$ was injected into the subphase (curve $B$ ). Curve $C$ represents the decrease in radioactivity elicited by LTC $(50 \mu \mathrm{g})$ which had been previously incubated with $2 \mathrm{mM} p$-chloromercuriphenyl sulfonate (PCMPS) for $30 \mathrm{~min}$ at $37^{\circ} \mathrm{C}$ prior to injection into the subphase. Middle panel. The monolayer consisted of $8 \mathrm{nmol}$ DOPC containing $5 \mathrm{~mol} \%$ tri $\left[{ }^{14} \mathrm{C}\right.$ oleoylglycerol. Curve D represents surface radioactivity in the absence of LTC. As is indicated by the arrow, LTC $(50 \mu \mathrm{g})$ was injected into the subphase (curves $E$ and $F$ ). Curve $E$ represents the decrease in radioactivity by LTC $(50 \mu \mathrm{g})$ which had been preincubated with $2 \mathrm{mM}$ PCMPS for $30 \mathrm{~min}$ at $37^{\circ} \mathrm{C}$ prior to injection into the subphase. Curve $F$ represents the decrease in radioactivity in the absence of PCMPS. Bottom panel. The monolayer consisted of either $8 \mathrm{nmol}$ phosphatidyl[ $\left.{ }^{14} \mathrm{C}\right]$ inositol (curve $\mathrm{H}$ ) or $8 \mathrm{nmol}\left[{ }^{14} \mathrm{C}\right]$ sphingomyelin (curve $\mathrm{G}$ ). As is indicated by the arrow, LTC $(50 \mu \mathrm{g})$ was injected into the subphase. proteins in solution. To determine whether LTC also removes lipids from monolayers, the complex was injected under a film containing various radiolabeled lipids, and changes in surface radioactivity and surface pressure were determined. Injection of LTC underneath a monolayer of DOPC containing $2 \mathrm{~mol} \%$ cholesteryl oleate causes a slight increase in surface pressure and a significant decrease in surface radioactivity, indicating a loss of $\left[{ }^{14} \mathrm{C}\right]$ cholesteryl oleate from the interface to the subphase (Fig. 1, top panel). Removal of cholesteryl oleate does not alter the surface pressure, probably due to the fact that removed lipid represents $<2 \%$ of the total lipid at the interface. The sulfhydryl reagent $p$-chloromercuriphenyl sulfonate (PCMPS), an inhibitor of triacylglycerol transfer $[32,33]$, does not influence the rate of removal of $\left[{ }^{14} \mathrm{C}\right]$ cholesteryl oleate from the interface as facilitated by LTC.

Fig. 1 (middle panel) also illustrates the effect of LTC on the removal of tri $\left[{ }^{14} \mathrm{C}\right.$ loleoylglycerol from a monolayer of DOPC. The LTC-facilitated decrease in surface tri $\left[{ }^{14} \mathrm{C}\right]$ oleoylglycerol radioactivity (curve F) corresponds to $2.5 \mathrm{nmol} \mathrm{h}^{-1} \cdot \mathrm{mg}^{-1}$ LTC. PCMPS $(2 \mathrm{mM})$ inhibits by $80 \%$ the rate of decreases in surface radioactivity (Fig. 1, curve E).

Monolayers of phosphatidyl[ $\left[{ }^{14} \mathrm{C}\right]$ inositol or $\left[{ }^{14} \mathrm{C}\right]$ sphingomyelin were spread at the air-water interface (Fig. 1, bottom). LTC removes $<5 \%$ of phosphatidyl[ $\left[{ }^{14} \mathrm{C}\right]$ inositol per $\mathrm{h}$; $\left[{ }^{14} \mathrm{C}\right]$ sphingomyelin is not removed.

The capacity of LTC to facilitate $\left[{ }^{14} \mathrm{C}\right]-$ cholesteryl oleate transfer from monolayer to subphase was compared with that of albumin, apolipoproteins, apolipoprotein-lipid complexes and lipoproteins (Fig. 2). With LTC, the decrease in surface radioactivity after $100 \mathrm{~min}$ corresponds to $50 \mathrm{pmol}\left[{ }^{14} \mathrm{C}\right] \mathrm{cholesteryl}$ oleate or $41 \%$ of the radiolabeled lipid in the monolayer. At this time, the subphase was collected and the cholesteryl ester radioactivity was determined; $49.1 \mathrm{pmol}$ of radiolabeled sterol was in the subphase indicating that the decrease in surface radioactivity was due to the transfer of lipid to the subphase. Analysis by thin-layer chromatography revealed that $>99 \%$ of the transferred lipid was $\left[{ }^{14} \mathrm{C}\right]$ cholesteryl ester. The lipoproteins and apolipoproteins tested are ineffective in removing $\left[{ }^{14} \mathrm{C}\right]$ cholesteryl oleate from a DOPC- $\left[{ }^{14} \mathrm{C}\right]$ cholesteryl oleate monolayer. Apo- 


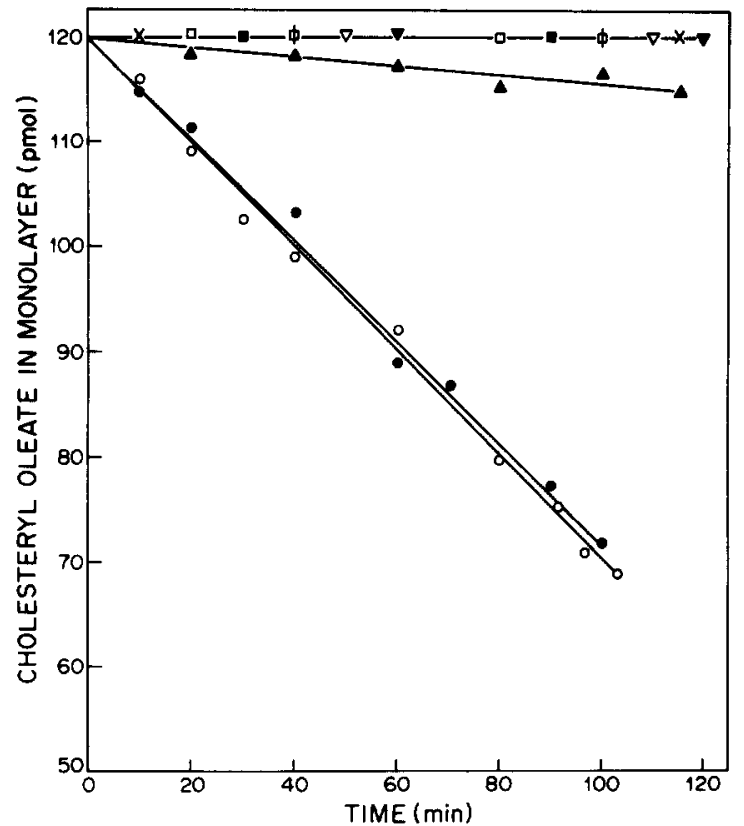

Fig. 2. Transfer of $\left[1-{ }^{14} \mathrm{C}\right]$ cholesteryl oleate from a dioleoylphosphatidylcholine (DOPC) monolayer to the subphase: role of lipid transfer complex. The monolayer contained $2 \mathrm{~mol} \%$ $\left[1-{ }^{14} \mathrm{C}\right]$ cholesteryl oleate in DOPC at an initial surface pressure of $20 \mathrm{mN} / \mathrm{m}$. The subphase contained $15 \mathrm{ml}$ of $10 \mathrm{mM}$ Tris- $\mathrm{HCl}, \mathrm{pH} 7.4,0.15 \mathrm{M} \mathrm{NaCl}$. The temperature was maintained at $37^{\circ} \mathrm{C}$. At time zero, either lipid transfer complex $(\mathrm{O}-\mathrm{O}, 95 \mu \mathrm{g} ; \bigcirc-0,380 \mu \mathrm{g}$ ), apolipoprotein C-I $\left(\square-\square, 50 \mu \mathrm{g}\right.$ ), apolipoprotein $\mathrm{C}-\mathrm{III}_{2}(\mathbf{\square - \square}, 50$ $\mu \mathrm{g})$, apolipoprotein A-I $(\nabla \longrightarrow \nabla, 50 \mu \mathrm{g})$, complexes of apolipoprotein A-I and sphingomyelin $(\nabla-\nabla, 150 \mu \mathrm{g}$ sphingomyelin), complexes of apolipoprotein $E$ and sphingomyelin (中- $中, 150 \mu \mathrm{g}$ sphingomyelin), fatty acid-free bovine serum albumin $\left(\Lambda-\Delta, 50 \mu \mathrm{g}\right.$ ), or $\mathrm{HDL}_{3}$ ( $\times \longrightarrow \times, 1 \mu \mathrm{mol}$ phospholipid) were injected into the subphase. The decrease in surface radioactivity was determined as described in Materials and Methods.

lipoprotein C-I $(50 \mu \mathrm{g})$, apolipoprotein $\mathrm{C}-\mathrm{III}_{2}$ (50 $\mu \mathrm{g})$, apolipoprotein A-I $(50 \mu \mathrm{g})$, sphingomyelinapolipoprotein A-I complexes $(150 \mu \mathrm{g}$ sphingomyelin), sphingomyelin-apolipoprotein $\mathrm{E}$ complexes (150 $\mu \mathrm{g}$ sphingomyelin), and $\mathrm{HDL}_{3}$ ( $1 \mu \mathrm{mol}$ phospholipid) do not remove $\left[{ }^{14} \mathrm{C}\right.$ [cholesteryl oleate. VLDL $(0.2 \mu \mathrm{mol}$ phospholipid), LDL ( $1 \mu \mathrm{mol}$ phospholipid) and sonicated egg phosphatidylcholine vesicles $(1 \mu \mathrm{mol})$ are without effect. However, fatty acid-free bovine serum albumin $(50 \mu \mathrm{g})$ removes a small amount of the cholesteryl oleate; the rate of removal of cholesteryl oleate from the monolayer by bovine serum albumin is one-twelfth the rate of removal in the presence of LTC. In contrast, human serum albumin in amounts as great as $100 \mu \mathrm{g}$ does not remove cholesteryl oleate from the monolayer (data not shown).

The dependence of the rate of $\left[{ }^{14} \mathrm{C}\right]-$ cholesteryl oleate removal from the interface on the concentration of the LTC added to the subphase is shown in Fig. 3. The removal of $\left[{ }^{14} \mathrm{C}\right]$ cholesteryl oleate from the phospholipid monolayer increases linearly with increasing amounts of LTC to a concentration of $100 \mu \mathrm{g}$ protein added to the subphase. The stoichiometric relationship between the amount of $\left[{ }^{14} \mathrm{C}\right]$ cholesteryl oleate removed and LTC is difficult to assess due to the uncertainty of the molecular weight of the LTC.

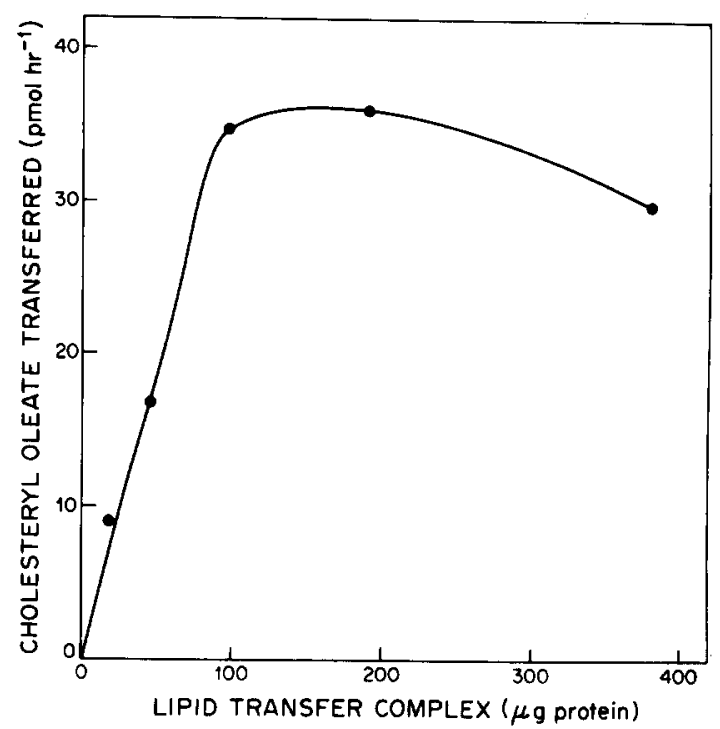

Fig. 3. Effects of lipid transfer complex concentration on the removal of $\left[1-{ }^{14} \mathrm{C}\right] \mathrm{cholesteryl}$ oleate from a dioleoylphosphatidylcholine (DOPC) monolayer. The monolayer contained $2 \mathrm{~mol} \%\left[1-{ }^{14} \mathrm{C}\right]$ cholesteryl oleate in DOPC in an initial surface pressure $20 \mathrm{mN} / \mathrm{m}$. The subphase contained $15 \mathrm{ml}$ of $10 \mathrm{mM}$ Tris- $\mathrm{HCl}, \mathrm{pH} 7.4,0.15 \mathrm{M} \mathrm{NaCl}$. The temperature was maintained at $37^{\circ} \mathrm{C}$. At time zero, the indicated amount of lipid transfer complex was added to the subphase. The rate of removal of $\left[1-{ }^{14} \mathrm{C}\right]$ cholesteryl oleate was determined by the loss of radioactivity from the interface as described in Materials and Methods. Each reaction was followed for $60 \mathrm{~min}$. Each experimental point represents the average of triplicate analysis; the error is $<8 \%$. 


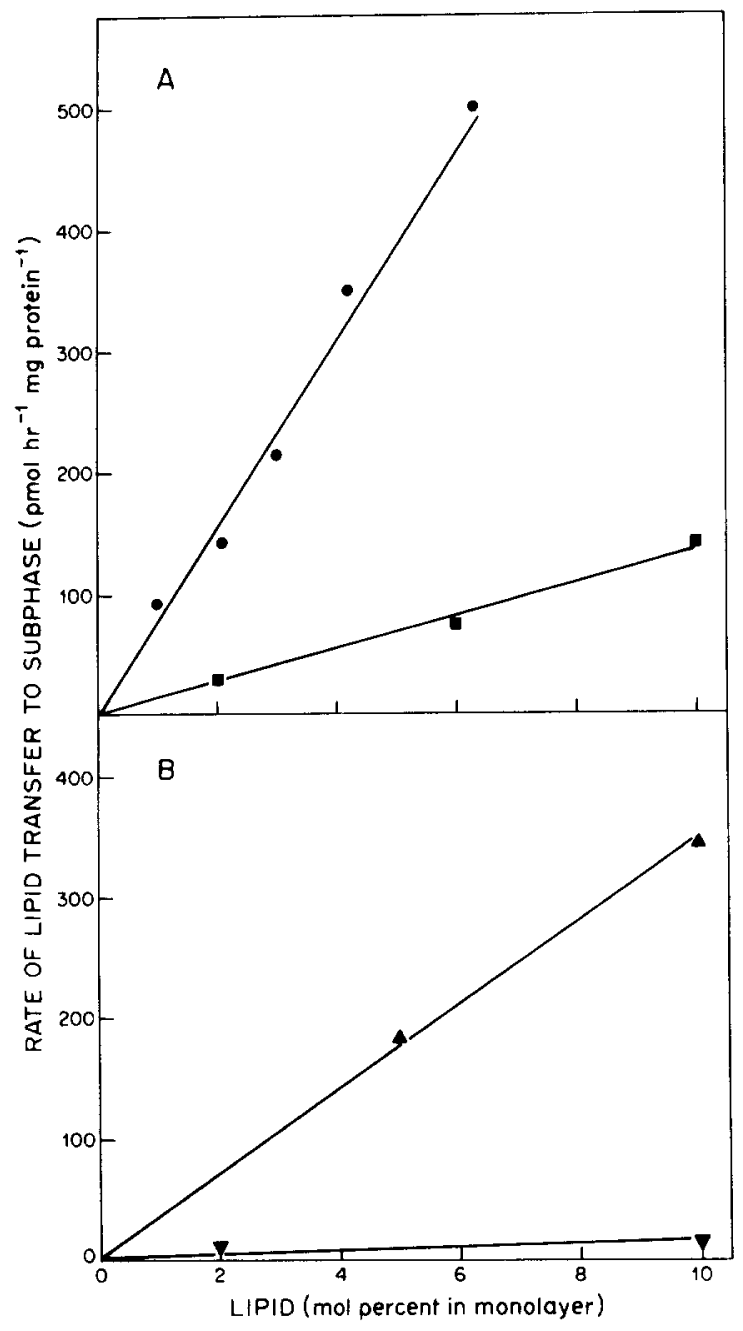

Fig. 4. Interaction of lipid transfer complex with other lipids. (A) The monolayer contained the indicated amount of [1$\left.{ }^{14} \mathrm{C}\right]$ cholesteryl oleate $(-\infty)$ or $\left[26-{ }^{14} \mathrm{C}\right]$ cholesterol ( $\square-\square)$ in dioleoylphosphatidylcholine. (B) The monolayer contained the indicated amount of 1-stearoyl-2oleoylphosphatidyl $\left[\mathrm{N}\right.$-methy $\left./{ }^{14} \mathrm{C}\right]$ choline in sphingomyelin $(\Delta-\Delta)$ or in sphingomyelin containing $4 \mathrm{~mol} \%$ cholesteryl oleate $(\boldsymbol{\nabla}-\boldsymbol{\nabla})$. The initial surface pressure in each monolayer was $20 \mathrm{mN} / \mathrm{m}$. The subphases contained $15 \mathrm{ml}$ of $10 \mathrm{mM}$ Tris-HCl, $\mathrm{pH} 7.4,0.15 \mathrm{M} \mathrm{NaCl}$. The temperature was maintained at $42^{\circ} \mathrm{C}$. The rate of removal of radiolabeled lipid was determined over a $60 \mathrm{~min}$ period. The experimental points represent the average of duplicate analysis with an average error of $<5 \%$.

The experiments described in Figs. 1-3 were performed with DOPC monolayers containing $2 \mathrm{~mol} \%\left[1-{ }^{14} \mathrm{C}\right]$ cholesteryl oleate. The data pre- sented in Fig. 4A indicate that the rate of lipid transfer to the subphase containing LTC is directly proportional to the amount of $\left[{ }^{14} \mathrm{C}\right]-$ cholesteryl oleate in the phospholipid monolayer up to $6 \mathrm{~mol} \%$ of $\left[{ }^{14} \mathrm{C}\right]$ cholesteryl oleate. Unesterified cholesterol is also transferred to the subphase from a phospholipid- $\left[{ }^{14} \mathrm{C}\right]$ cholesterol monolayer in the presence of LTC (Fig. 4A), and the rate of cholesterol removal increases linearly with increasing concentration of cholesterol in DOPC. However, the rate of LTC-facilitated $\left[{ }^{14} \mathrm{C}\right]$ cholesterol removal is only $15 \%$ of that of $\left[{ }^{14} \mathrm{C}\right]$ cholesteryl oleate removal.

Relationship between removal of neutral lipid and phospholipid facilitated by LTC

LTC transfers both cholesteryl ester and phosphatidylcholine between lipoproteins with a $1: 1$ stoichiometry and at equal rats of flux [19]. The next series of monolayer studies were designed to determine whether the transfer of cholesteryl oleate from the monolayer to the subphase containing LTC is coupled to transfer of phosphatidylcholine. For these experiments, the monolayer contained bovine brain sphingomyelin and various amounts of ${ }^{14} \mathrm{C}$-labeled egg phosphatidylcholine and/or $\left[{ }^{14} \mathrm{C}\right]$ cholesteryl oleate. As is shown in Table I, the rate of LTC-enhanced removal of $\left[{ }^{14} \mathrm{C}\right]$ cholesteryl oleate from a monolayer of sphingomyelin is ap-

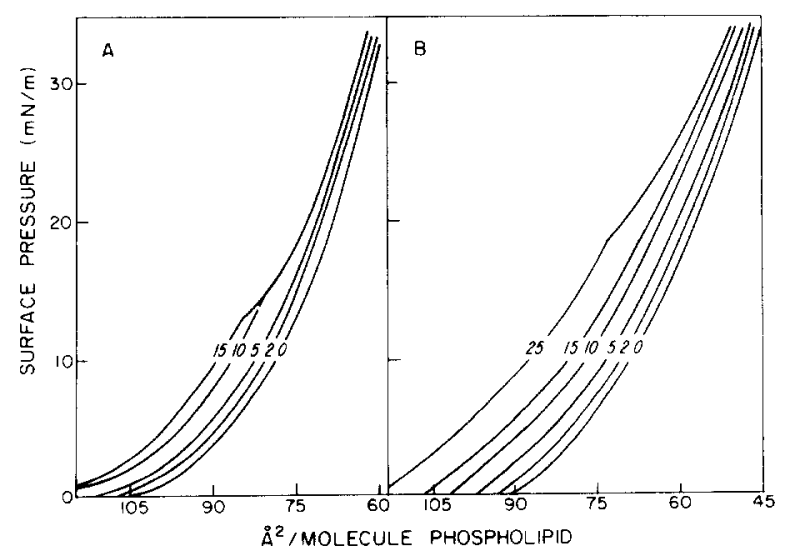

Fig. 5. Force-area curves for cholesteryl oleate in dioleoylphosphatidylcholine (A) and in sphingomyelin (B). The mol\% of cholesteryl oleate in each colipid is indicated. The subphase contained $10 \mathrm{mM}$ Tris- $\mathrm{HCl}, \mathrm{pH} 7.4,0.15 \mathrm{M} \mathrm{NaCl}$. The temperature was maintained at $42^{\circ} \mathrm{C}$. 
TABLE I

DEPENDENCE ON MONOLAYER COMPOSITION OF THE FACILITATED TRANSFER OF [1$\left.{ }^{14} \mathrm{C}\right]$ CHOLESTERYL OLEATE AND TRI $\left[{ }^{14} \mathrm{C}\right]$ OLEOYLGLYCEROL TO THE SUBPHASE

$\left[1-{ }^{14} \mathrm{C}\right]$ Cholesteryl oleate (CO) or tri $\left[{ }^{14} \mathrm{C}\right.$ oleoylglycerol (TO) were incorporated into sphingomyelin (Sph) and egg phosphatidylcholine (PC) monolayers as described in Materials and Methods. Lipid transfer complex ( $100 \mu \mathrm{g}$ protein) was injected into the subphase, and the rate of loss of radioactivity from the monolayer was assessed at $42^{\circ} \mathrm{C}$.

\begin{tabular}{cccclll}
\hline \multicolumn{3}{l}{ Monolayer composition (mol\%) } & & \multicolumn{2}{l}{$\begin{array}{l}\text { Lipid transferred } \\
\left(\mathrm{nmol} \cdot \mathrm{h}^{-1} \cdot \mathrm{mg}^{-1}\right)\end{array}$} \\
\hline Sph & PC & TO & CO & & \multicolumn{2}{l}{} \\
\cline { 6 - 7 } & & & & & TO & CO \\
\hline 96.0 & - & - & 4.0 & - & 0.029 \\
86.6 & 9.6 & - & 3.8 & & - & 0.235 \\
24.0 & 72.2 & - & 3.8 & & - & 0.321 \\
- & 96.0 & - & 4.0 & & - & 0.335 \\
95.0 & - & 5.0 & - & 3.14 & - \\
85.4 & 9.8 & 4.8 & - & 3.27 & - \\
- & 95.0 & 5.0 & - & 2.49 & - \\
\hline
\end{tabular}

prox. $10 \%$ of that from a phosphatidylcholine monolayer, $2.9 \mathrm{pmol} \cdot \mathrm{h}^{-1} \cdot \mathrm{mg}^{-1}$ compared to 33.4 $\mathrm{pmol} \cdot \mathrm{h}^{-1} \cdot \mathrm{mg}^{-1}$. Upon addition of approx. 10 mol\% phosphatidylcholine to the sphingomyelin monolayer, the rate of $\left[{ }^{14} \mathrm{C}\right]$ cholesteryl oleate removal increases to $23.5 \mathrm{pmol} \cdot \mathrm{h}^{-1} \cdot \mathrm{mg}^{-1}$. With 72 mol\% phosphatidylcholine and $24 \mathrm{~mol} \%$ sphingomyelin, the rate of sterol removal is nearly the same as that from a phosphatidylcholinecholesteryl oleate monolayer.

Although the LTC-facilitated transfer of $\left[{ }^{14} \mathrm{C}\right]$ cholesteryl oleate is dependent on phosphatidylcholine, the transfer of $\operatorname{tri}\left[{ }^{14} \mathrm{C}\right]$ oleoylglycerol to the subphase containing LTC is not (Table I). The rate of transfer of triacylglycerol is $3.14 \mathrm{nmol}$ transferred per $\mathrm{h}$ per $\mathrm{mg}$ protein in the absence of phosphatidylcholine and 3.27 in the presence of $9.8 \mathrm{~mol} \%$ phosphatidylcholine. These values are comparable to $2.49 \mathrm{nmol}$ triacylglycerol transferred per $h$ per $\mathrm{mg}$ protein in a film containing $95 \mathrm{~mol} \%$ phosphatidylcholine (Table I).

The results summarized in Table $I$ indicate that the removal of cholesteryl oleate but not triacylglycerol from a sphingomyelin monolayer by
LTC depends on the presence of phosphatidylcholine. To determine the role of phospholipid in the exchange process, radiolabeled phosphatidylcholine was incorporated into the monolayer in order to determine whether LTC also removes phosphatidyl $\left[{ }^{14} \mathrm{C}\right]$ choline from the monolayer, and whether the rate of removal of phosphatidylcholine depends on the presence of cholesteryl oleate. As is shown in Fig. 4B, 1-stearoyl-2-oleoyl phosphatidyl $\left[N\right.$-methyl $\left.{ }^{14} \mathrm{C}\right]$ choline is transferred from sphingomyelin monolayers prepared in the absence of cholesteryl oleate to the subphase containing LTC. However, the addition of $4 \mathrm{~mol} \%$ cholesteryl oleate to the phosphatidylcholine-sphingomyelin monolayer completely inhibits phosphatidylcholine removal.

\section{Monolayer properties}

To obtain information about the state of cholesteryl oleate in the lipid monolayers, compression curves for the ester in DOPC and in sphingomyelin were determined as a function of the mole fraction of cholesteryl oleate. The equilibrium spreading pressure of cholesteryl oleate alone is about zero $\mathrm{mN} / \mathrm{m}$. When mixed with DOPC at the air-water interface, cholesteryl oleate causes a shift in the force-area curve of DOPC as is indicated in Fig. 5A. Concentrations of cholesteryl oleate of $5 \mathrm{~mol} \%$ and less are completely miscible with DOPC even at high surface pressures. At concentrations of cholesteryl oleate greater than $10 \mathrm{~mol} \%$ the force-area curves break at surface pressures just above $10 \mathrm{mN} / \mathrm{m}$, indicating that cholesteryl oleate has been forced out of the monolayer. The force-area curves are reversible which suggests that, at the higher surface pressures, cholesteryl oleate in the monolayer is in equilibrium with the cholesteryl oleate in the bulk phase.

Cholesteryl oleate is more miscible in monolayers of bovine brain sphingomyelin compared to DOPC as is demonstrated in Fig. 5B. At all surface pressures, sphingomyelin accomodates as much as $15 \mathrm{~mol} \%$ cholesteryl oleate. At the highest concentration of cholesteryl oleate, $25 \mathrm{~mol} \%$, the lipids are completely miscible until the surface pressure approaches $20 \mathrm{mN} / \mathrm{m}$. Identical force-area curves occur with sphingomyelin purified from erythrocytes. Moreover, the addition of DOPC, final con- 
centration $10 \mathrm{~mol} \%$, does not alter the compression curves of sphingomyelin and does not affect the solubility of cholesteryl oleate in the monolayers (data not shown).

\section{Discussion}

The lipid monolayer system was utilized for quantitating the lipid specificity and lipid binding properties of a lipid transfer complex (LTC) isolated from human plasma. LTC facilitates the removal of cholesteryl oleate, trioleoylglycerol, phosphatidylcholine and, to a lesser extent, cholesterol from binary and ternary lipid monolayers. The rate of lipid removal depends on the lipid composition of the monolayer, the amount of reactive lipid in the interface, and the concentration of LTC. The LTC-factilitated transfer of trioleoylglycerol is inhibited by PCMPS, whereas the transfer of cholesteryl ester is not affected.

Interpretation of these monolayer studies requires an understanding of the structure of the lipid monolayers. The data in Fig. 5 indicate that cholesteryl oleate is miscible in amounts of up to 5 or $15 \mathrm{~mol} \%$, respectively, in monolayers of dioleoylphosphatidylcholine or sphingomyelin. At the concentrations of cholesteryl oleate employed in this investigation $(\leqslant 6 \mathrm{~mol} \%)$ and at pressures below the collapse pressure, the force-area curves are completely reversible. Furthermore, with each increasing concentration of cholesteryl oleate added to the colipid monolayer, there is a corresponding linear expansion of the monolayer indicating uniform molecular packing of the lipids. The reason for the increased miscibility of cholesteryl oleate in sphingomyelin compared to DPOC is not evident. However, it is known that sphingomyelin is more effective than phosphatidylcholine in maintaining bilayer structures in systems containing cholesterol [34].

The lipid transfer protein complex isolated from human lipoprotein-free plasma removes, in a concentration-dependent process, cholesteryl ester from a monolayer of cholesteryl oleate and dioleoyl phosphatidylcholine. The ability to remove cholesteryl oleate is specific for LTC since there is a negligible amount of ester removed by serum albumin, the plasma lipoproteins or the purified apolipoproteins. Due to the limited amount of lipid and LTC in the system, it was not possible to reisolate the LTC after removal of monolayer lipids so as to determine the mechanism of lipid transfer. The LTC could facilitate net lipid removal or alternatively lipid contained within the LTC could exchange with the monolayer lipids. Purified LTC contains approx. 7\% (w/w) lipid [28]. Regardless of the mechanism of lipid transfer, in the absence of monolayer phosphatidylcholine (Table I), the rate of LTC-catalyzed transfer of cholesterol oleate from a sphingomyelin monolayer to the subphase is $10 \%$ of that from a monolayer containing 10 mol\% phosphatidylcholine in sphingomyelin. Addition of greater concentrations of phosphatidylcholine elicits only small further increases in the transfer rate. Since there are no differences in the compression curves of sphingomyelin in the presence and absence of $10 \%$ phosphatidylcholine (data not shown), it seems unlikely that the low rate of removal of cholesteryl oleate in the absence of phosphatidylcholine is due to increased interaction of the cholesteryl ester with sphingomyelin. An alternative explanation is that phosphatidylcholine is required for cholesteryl ester transfer by the lipid-transfer protein complex. In this regard, Ihm et al. [19] have demonstrated that LTC transfers cholesteryl esters and phosphatidylcholine between lipoproteins with $1: 1$ stoichiometry and at equal rates of flux. However, under the conditions of the experiments reported herein, LTC-facilitated removal of cholesteryl ester and phosphatidylcholine from the lipid interface is not a stoichiometric process. LTC removes cholesteryl oleate but not phosphatidylcholine (Table I and Fig. 4B) from a monolayer of cholesteryl oleate/DOPC/sphingomyelin $(4: 10: 86, \mathrm{~mol} \%)$ and phosphatidylcholine from an interface of DPPC/sphingomyelin (10:90, mol\%). Thus, cholesteryl ester, but not phosphatidylcholine, is removed from ternary lipid monolayers. These results, combined with the finding that PCMPS does not inhibit LTC-facilitated removal of cholesteryl ester or phosphatidylcholine but does inhibit removal of trioleoylglycerol, are consistent with the existence of three lipid transfer proteins, one specific for cholesteryl ester, one specific for triacylglycerol and one specific for phosphatidylcholine. It is also possible but unlikely that a single transfer protein with three distinct lipid transfer activities exists. 
Although further studies are required to resolve the status of the lipid transfer protein(s) and to determine the factors which govern lipid specificity, the present findings are of interest since they are relevant to lipoprotein metabolism. The fact that the rate of cholesteryl ester removal by LTC is directly proportional to the concentration of the lipid in the monolayer suggests that the reactive cholesteryl esters in lipoproteins are those situated in the surface rather than the core of the lipoprotein particles. The consequences of this prediction are three. First, the rate of cholesteryl ester transfer from a lipoprotein is contingent on the concentration of the ester in the lipoprotein surface. Second, the direction of cholesteryl ester transfer ought to occur down a concentration gradient with respect to donor and acceptor lipoprotein interfaces. Third, the rate of transfer will be modulated by the composition and structure of the surface of donor and acceptor lipoproteins.

\section{Acknowledgements}

This research was supported by National Institutes of Health Grant HL 22619 and HL 23019 and by a Basic Research Science Grant from the University of Cincinnati. J.A.K. Harmony is an Established Investigator of the American Heart Association. The authors are indebted to Rose Alden and Janet Simons for preparation of the manuscript, and to Gwen Kraft and Roger Purcell for the artwork.

\section{References}

1 Jackson, R.L., Morrisett, J.D. and Gotto, A.M. (1976) Physiol. Rev. 56, 259-316

2 Smith, L.C., Pownall, H.J. and Gotto, A.M. (1978) Annu. Rev. Biochem. 47, 751-777

3 Osborne, J.C. and Brewer, H.B. (1977) Adv. Protein Chem. 31, 253-337

4 Scanu, A.M. and Landsberger, F.R. (1980) Ann. N.Y. Acad. $348,1-434$

5 Schaefer, E.J., Eisenberg, S. and Levy, R.I. (1978) J. Lipid Res. 19, 667-687

6 Smaby, J.M. and Brockman, H.L. (1978) J. Lipid Res. 19 , 325-331
7 Smaby, J.M., Baumann, W.J. and Brockman, H.L. (1979) J. Lipid Res. 20, 789-795

8 Smaby, J.M. and Brockman, H.L. (1981) Biochemistry 20, 718-723

9 Smaby, J.M. and Brockman, H.L. (1981) Biochemistry 20, 724-730

10 Janiak, M.J., Loomis, C.R., Shipley, G.G. and Small, D.M. (1974) J. Mol. Biol. 86, 325-339

11 Janiak, M.J., Small, D.M. and Shipley, G.G. (1979) J. Lipid Res. 20, 183-199

12 Loomis, C.R., Janiak, M.J., Small, D.M. and Shipley, G.G. (1974) J. Mol. Biol. 86, 309-324

13 Deckelbaum, R.J., Shipley, G.G. and Small, D.M. (1977) J. Biol. Chem. 252, 744-754

14 Nichols, A.V. and Smith, L. (1965) J. Lipid Res. 6, 206-210

15 Chajek, T. and Fielding, C.J. (1978) Proc. Natl. Acad. Sci. U.S.A. 75, 3445-3449

16 Barter, P.J. and Jones, M.E. (1979) Atherosclerosis 34, 67-74

17 Zilversmit, D.B., Hughes, L.B. and Balmer, J. (1974) Biochim. Biophys. Acta 409, 393-398

18 Rajaram, O.V. and Barter, P.J. (1980) Biochim. Biophys. Acta 620, 483-488

$19 \mathrm{Ihm}$, J., Harmony, J.A.K., Ellsworth, J. and Jackson, R.L. (1980) Biochem. Biophys. Res. Commun. 93, 1114-1120

20 Van Deenen, L.L.M. and De Haas, G.H. (1964) Adv. Lipid Res. 2, 167-234

21 Stoffel, W., Lekim, D. and Tschung, T.S. (1971) HoppeSeyler's Z. Physiol. Chem. 352, 1058-1064

22 Demel, R.A., Kalsbeek, R., Wirtz, K.W.A. and Van Deenen, L.L.M. (1977) Biochim. Biophys. Acta 466, 10-22

23 Jackson, R.L., Baker, H.N., Gilliam, E.B. and Gotto, A.M. (1977) Proc. Natl. Acad. Sci. U.S.A. 74, 1942-1945

24 Catapano, A.L., Jackson, R.L., Gilliam, E.B., Gotto, A.M. and Smith, L.C. (1978) J. Lipid Res. 19, 1047-1052

25 Baker, H.N., Jackson, R.L. and Gotto, A.M. (1973) Biochemistry $12,3866-3871$

26 Shelburne, F.A. and Quarfordt, S.H. (1977) J. Clin. Invest. $60,944-950$

27 Socorro, L. and Camejo, G. (1979) J. Lipid Res. 20, 631-638

$28 \mathrm{Ihm}$, J., Ellsworth, J., Chataing, B. and Harmony, J.A.K. (1982) J. Biol. Chem. 257, 4818-4827

29 Lowry, O.H., Rosebrough, N.J., Farr, A.L. and Randall, R.J. (1951) J. Biol. Chem. 193, 265-275

30 Bartlett, G.R. (1959) J. Biol. Chem. 234, 466-468

31 Roeschlau, P., Bernt, E. and Gruber, W. (1974) Z. Klin. Chem. Biochem. 12, 403-407

32 Ellsworth, J.L. and McVittie, L. (1981) Fed. Proc. 40, 1695 (Abstr.)

33 Barter, P.J., Gooden, J.M. and Rajaram, O.V. (1979) Atherosclerosis 33, 165-169

34 Cullis, P.R. and Hope, M.J. (1980) Biochim. Biophys. Acta 597, 533-542 